na con Ángeles, del retablo de Santa Ana de la Colegiata de Játiva y con la Madona del Museo de Artes Decorativas de París (Fig. 8). Por la foto que reproduce Gaya Nuño de ella ${ }^{5}$, podemos observar que la tabla actualmente se halla restaurada, y en ciertas zonas excesivamente, aunque no afecta a partes importantes de la obra.

ISABEL MATEO GÓMEZ

Dpto. H. ${ }^{a}$ del Arte del CSIC

\title{
EL RETABLO MAYOR DE LA CATEDRAL DE ASTORGA. UN CONCURSO ESCULTORICO EN LA ESPAÑA DEL RENACIMIENTO
}

Durante el obispado de Don Diego Sarmiento de Sotomayor en la ciudad de Astorga, en la provincia de León, se llevó a cabo, en el año 1558, el concurso para la ejecución del retablo mayor de la catedral de Astorga. Tres propuestas de escultores fueron presentadas al obispo y al cabildo del templo astorgano: el 26 de marzo del 1558 la de los escultores Juan Picardo y su yerno Pedro Andrés «estantes en Medina del Campo»; el 22 de mayo, la del grupo de escultores palentinos, Miguel Alvarez, Juan Ortiz y Luis Ortiz y el 8 de agosto la del escultor y pintor baezano Gaspar Becerra. En 1908, los tres proyectos fueron mencionados por primera vez, por Pedro Rodríguez López, pero sólo la del vencedor Becerra fue publicado ${ }^{1}$. Descuido o desinterés, que llama la atención si pensamos que Picardo y Alvarez fueron considerados por sus contemporáneos los «mejores oficiales que al presente ay en estos Reynos en el oficio e arte de ymaginería e de los bultos» en España ${ }^{2}$. La comparación de estos dos proyectos inéditos, que logré identificar en el Archivo Diocesano de Astorga, con el de Becerra, analizado en el 1969 por Juan José Martín González, completa el conocimiento sobre uno de los concursos escultóricos más importantes de la España del Renacimiento.

Juan Picardo y Pedro Andrés prometían concluir el trabajo en 5 años, por un total de 2.500 ducados ${ }^{3}$, mientras que Miguel Alvarez, Juan Ortiz y Luis Ortiz se obligaban a terminar el retablo mayor en tres años, por 300 ducados más que los anteriores ${ }^{4}$. Sin embargo, el 24 de mayo, después de haber visto la traza presentada por Picardo y Andrés y haber leído la propuesta de éstos, los palentinos decidieron rebajar la demanda inicial a 2.300 ducados, o sea a 200 ducados menos que Picardo y Andrés. Lo curioso de esta enmienda es que los palentinos estaban no sólo dispuestos a abandonar su propio proyecto, sino que se ofrecían, por esta suma de dinero, realizar el retablo mayor siguiendo las instrucciones de los otros dos escultores: «manuel álvarez e luis ortiz e juan ortiz, vezinos de la çiudad de palençia, escultores, dixeron [...], que harán el dicho rretablo conforme a la dicha muestra, hecha e dada por los dichos juan picardo e pedro an-

\footnotetext{
${ }^{5}$ Gaya, Nuño: La Pintura española fuera de España, Madrid, 1958, lám. 47, cat. n. ${ }^{\circ}$ 1.511, entonces en la Arcade Gallery de Lóndres y hoy felizmente recuperada.

${ }^{1}$ Rodríguez López, P.: Episcopologio asturicense, vol. III, Astorga, 1908, pp. 41, 172-179 y Rodríguez Díez, M.: Historia de la muy Noble, Leal y Benemérita Ciudad de Astorga (1909), Astorga, 1981, pp. 802-806.

${ }^{2}$ Martí y Monsó, J.: Estudios histórico-artísticos, relativos principalmente a Valladolid, Valladolid, 1898-1901, p. 178

3 «Postura del rretablo dela y[gles]ia cathedral», 26 de marzo 1558, 3 fols. Leg.: Íñigo de Miranda-1558, Archivo Diocesano de Astorga (A.D.A.).

4 «Postura del rretablo dela yglesia cathedral de astorga q[ue] hizieron los de palençia», 22 de mayo de 1558, 6 fols. Leg.: Íñigo de Miranda-1558 (sin catalogar), A.D.A.
} 
drés e con las condiçiones e postura que ellos la pusieron e se obligaron a lo hazer e con cada una dellas por dos myll e treçientos ducados e por el dicho preçio, harán el dicho rretablo, según dicho» ${ }^{5}$. Estas dos propuestas quizá se habían reducido a una sola, cuando Gaspar Becerra entregó su proyecto, que fue aprobado en agosto del mismo año. En el documento, el baezano se comprometía a llevar a cabo la obra en dos años, pero exigía 3.000 ducados, la suma más alta para la realización del retablo catedralicio.

Los grupos encabezados respectivamente por Picardo y Alvarez habían concebido un retablo de cuatro órdenes sobre banco y coronados por ático, contrariamente a Becerra, que había propuesto un retablo de tres cuerpos con predela y remate.

Las primeras dos propuestas tienen en común el énfasis en la verticalidad de la obra, que se conseguiría al dar mayor resalto a la calle central, con portadas más altas y anchas para contener la custodia desde el banco hasta el primer cuerpo y en los tres cuerpos superiores, esculturas exentas. En el caso de Picardo y Andrés, la continuidad horizontal del retablo se vería comprometida, por una parte, al adoptar tres encasamientos para las historias del cuerpo superior, en contraste con las cuatro portadas laterales de los órdenes inferiores y por otra parte, a causa de la diferencia de medidas de altura y de ancho de las «caxas» en los cuatro cuerpos ${ }^{6}$. El proyecto de los palentinos, en cambio, se concentra casi exclusivamente en la descripción temática y decorativa, tanto de la calle central del retablo, como del remate de la obra ${ }^{7}$. Se da gran resalto a la descripción de los motivos decorativos del retablo, como la presencia de tarjas, serafines, figurillas vestidas, virtudes, niños, ángeles con festones de frutas, hojas, florón, utilizados en función unitaria de los elementos arquitectónicos y de la temática del retablo ${ }^{8}$. La definición arquitectónica y medidas de las dieciséis portadas laterales, distribuidas equitativamente en los 4 órdenes, ocupa un lugar secundario. El poco espacio concedido a la arquitectura del retablo, en este proyecto, consiste en la declaración del uso indiscriminado de columnas grandes y pequeñas, jónicas y corintias, con la presencia de esculturas exentas entre ellas y de otras encima de éstas ${ }^{9}$.

El enfoque del proyecto de Becerra, se concentra, como se sabe, exclusivamente en la arquitectura del retablo mayor y contrariamente a los dos anteriores, en el uso claro, ordenado y coherente de los órdenes arquitectónicos ${ }^{10}$. Becerra recomienda que en el primer cuerpo, las columnas, capiteles, basas y friso estén totalmente cubiertos de follamen de talla. La exuberancia manifiesta en este orden será reducida en los cuerpos superiores en función de una mayor claridad estructural. Por consiguiente, las columnas del segundo cuerpo, en estilo «compósito», «que adornan los quadros y rigen la arquitectura», presentarían un tercio entallado y dos tercios estriados, y el friso sería de «talla hordenada». El mismo criterio se aplicaría en el cuerpo superior, en donde los «dentículos y óbalos» son los únicos ornamentos recomendados para las molduras de las portadas. En el remate se distribuirían esculturas de la Crucifixión, de la Virgen, de San Juan y de 10 ángeles. Las catorce portadas de igual medida, se distribuirían equitativamente en los tres cuerpos, llegando a mantener un equilibrio entre la verticalidad y horizontali-

5 «Postura del rretablo desta santa yglesia de los de palençia», 24 de mayo de 1558, 1 fol. Leg.: Íñigo de Miranda1558 (sin catalogar), A.D.A., fol. 1r.

626 de marzo de 1558, 3 fols. Leg.: Íñigo de Miranda-1558, A.D.A. Las portadas del primer cuerpo de 7 pies de altura, tendrían 4 pies y medio de alto por 4 y medio de ancho, con excepción de la caja de la custodia que tendría 5 pies de alto. Las portadas del segundo cuerpo, de donde se levantarían 4 columnas corintias de entrecalle, de 14 pies de altura, que conservarían la misma anchura de las cajas «baxeras», tendrían 6 pies de alto, mientras que las del tercer orden, serían más anchas y tendrían 7 pies de altura. Los encasamientos del segundo orden estarían dividos por columnas dóricas y las del orden superior por columnas corintias. La «caxas» del cuarto orden, con sus columnas del género compuesto, tendrían 8 pies de altura y la del medio tendría 6 pies de ancho. En el remate se reprentaría el Calvario (fols. 1v-1r).

722 de mayo de 1558, 6 fols. Leg.: Íñigo de Miranda-1558, A.D.A., fols. 1v-4r. Ver nota 16.

${ }^{8}$ Ibidem, fols. $4 \mathrm{r}-5 \mathrm{v}$

${ }^{9}$ Ibidem, fols. $1 \mathrm{r}-2 \mathrm{v}$

${ }^{10}$ Martín González, J. J.: «Precisiones sobre Gaspar Becerra», Archivo Español de Arte, XLII, 1969, pp. 339-342. 
dad del retablo: «las ystorias que bienen en los espacios que quedan entre las colunas, las quales serán de seis pies y más de ancho y la alteza será de nuebe pies». Las historias sagradas, que se entallarían en bajo relieve, serían elegidas por las autoridades eclesiásticas ${ }^{11}$.

A diferencia de Becerra, los otros escultores especifican las historias sagradas que se representarían en el altar mayor. Los palentinos se limitan a describir aquellas que ocuparían la calle central, «ençima de la custodia»: Oración del Huerto, Dormición de la Virgen, La Asunción de la Virgen, La Coronación de la Virgen y el Calvario ${ }^{12}$, mientras que Picardo y Andrés ofrecen una lista detallada de todas las historias sagradas, que son diecisiete, a ejecutarse en bajo relieve: El Abrazo de S. Joaquín y Sta. Ana, La Natividad de la Virgen, La Presentación de la Virgen en el templo, Los Desposorios de la Virgen con S. José, La Anunciación, La Visitación, La Adoración de los Magos, La Circuncisión, La Adoración de los pastores, La Presentación de Jesús en el templo, Huída a Egipto, Jesús entre los doctores, La Piedad, La Ascensión, Entierro de Cristo, La Asunción de la Virgen y La Coronación de la Virgen ${ }^{13}$.

Los palentinos y Becerra dedican un espacio relevante a la custodia del retablo, mientras que Picardo y Andrés sólo se limitan a dar las medidas del encasamiento que la albergaría. Los primeros describen un cuerpo transparente y circular rodeado por columnas pareadas y frisos con ángeles, en cuyo interior se vería la custodia del Santísimo en forma de sepulcro con la imagen del Cristo yacente, sostenido por ángeles. Este primer cuerpo estaría coronado por cimborrio con pilares cuadrados, donde se colocaría la escultura de la Virgen y el Niño ${ }^{14}$. Becerra, que considera la custodia como algo separado, lo concibe como un templo cerrado de tres cuerpos. Recomienda el orden dórico en el primer cuerpo, con ángeles en el frontespicio. En la puerta de la custodia, a cuyos lados se colocaría una escultura de santo, se entallaría en bajo relieve el Triunfo de Cristo. Becerra sugiere el orden corintio para los cuerpos superiores del tabernáculo, en donde la decoración dependería del juicio del artista ${ }^{15}$.

$\mathrm{El}$ andaluz fue el único artista que propuso la ejecución previa de una de las historias del retablo: la escultura de Nuestra Señora de la Asunción (Fig. 10) para que las autoridades ecle-

11 Rodríguez López, pp. 173-174.

1222 de mayo de 1558, 6 fols. Leg.: Íñigo de Miranda-1558, A.D.A., fols. 1v-4r: «ençima desta custodia a de aber la istoria/ del monte tabor y ençima desta ystoria a de auer/ un pabellón, que le tengan unos serafines, que/ le tengan por la parte de ariba y por la parte de los ri-/ ncones de la caxa, a de aber otros serafines, que/ le tengan y debaxo del pabellón, a de aber un pi-/ tafio, que le tengan dos angelles, en el qual epeta-/ fio se pondrá la letras de la istoria y esta caxa/ a de tener de ancho, cinco pies y medio...» (fol. 2r); en el tercero «a de auer el tránsito de nuestra señora, confor-/ me como está debujado en la traza y esta caxa a de/ ser con las demás de la calle de medio, a de ser hu-/ eca acia dentro y debaxo de la cornjsa del tránsito,/ a de auer un florón grande y por de dentro, una/ benera, a manera de un aobado...» (fol. 3v); y en el cuarto orden se colocaría «una ystoria de la asunçión de nuestra señora, con ocho há-/ ngeles y su luna debaxo de los pies y un trono de serafines, como esté la luna metida/ entre hellos...» (fol. $3 \mathrm{v}$ ). Este encasamiento culminaría con un cimborio «alto [...] y taberná-/ culo, [que] a de ser medio rredondo, azia la parte de fuera», en cuyo interior «a de benir una istoria de la coronaçión de nuestra/ señora» (fol. 4v). Encima de la cornisa del cimborio, entre seis columnas pareadas «a de aber nuestra señora y san juan, como/ están al pie de la cruz» (fol. 4r). Esta estructura complicada culminaría con la Crucifixión.

1326 de marzo 1558, 3 fols. Leg.: Íñigo de Miranda-1558, fols. 3v-3r. La lista explicativa de las historias sagradas fue escrita en un documento separado y añadido al final de la propuesta presentada por Picardo y Andrés.

1422 de mayo de 1558, 6 fols. Leg.: Íñigo de Miranda-1558 (sin catalogar), A.D.A.: «una custodia rredonda trasparente/ y toda de colunas alrededor, de en dos en dos, como se pare-/ ce estar debuxado y a de aber dentro de la custodia,/ una caxa donde a de estar el santísimo sacramento,/ a manera de un sepulcro y éste le an de tener unos/ ángeles y encima estaría cristo, como está sepultado/ y esto, a de ser de bulto redondo, que se be por todas/ partes, por entre las colunas, y adihas./ Ytem más que hençima destas colunas de la custodia/ bendrá un alquitraue y friso y cornjsa, labrados,/ los frisos de njños y angélicos, por que conbiene/ para la tal obra y encima desta cornjsa a de/ aber otro cuerpo, a la manera de un cinbodio y a/ de aber unos pilares quadrados, que reçiban/ un alquitraue y friso y cornjsa y ençima de la cornj-/ sa, a de auer un cinbodio [...] a de auer una nuestra señora asentada con su njño y a/ los lados, a de auer unos quadros con sus molduras/ que vayan buscando el redondo del mesmo cinbodio y/ ençima destos quadros, a de auer unos njños sen-/ tados, que tengan unos festoncicos en las manos,/ de frutas, por que después de pintados, serán/ los njños encarnados y las frutas dadas sus co-/ lores y así no se parecerá cada cosa lo que es...» (fols. 2v-3r).

15 Rodríguez López, op. cit., pp. 174-175. 


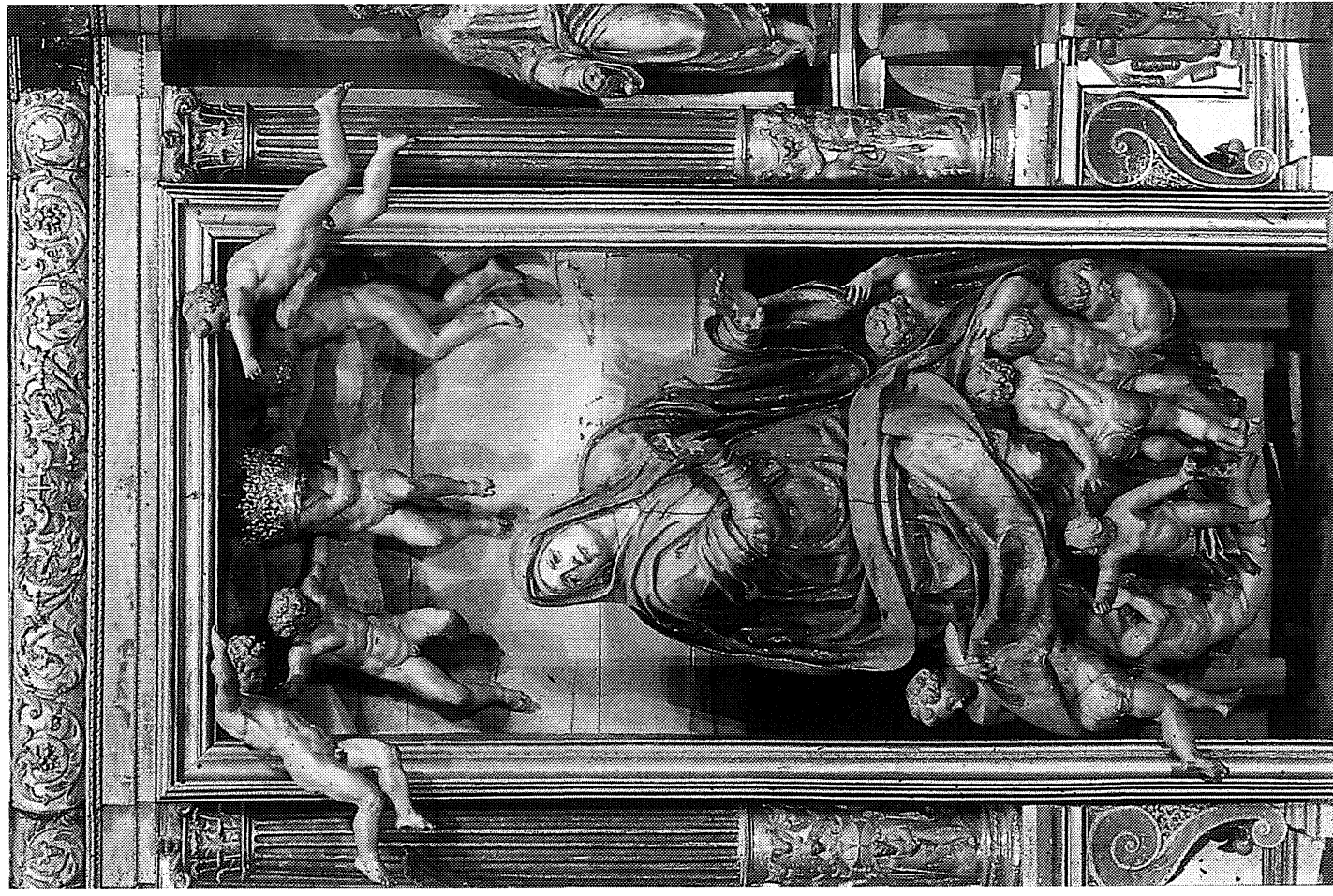

$\circ$

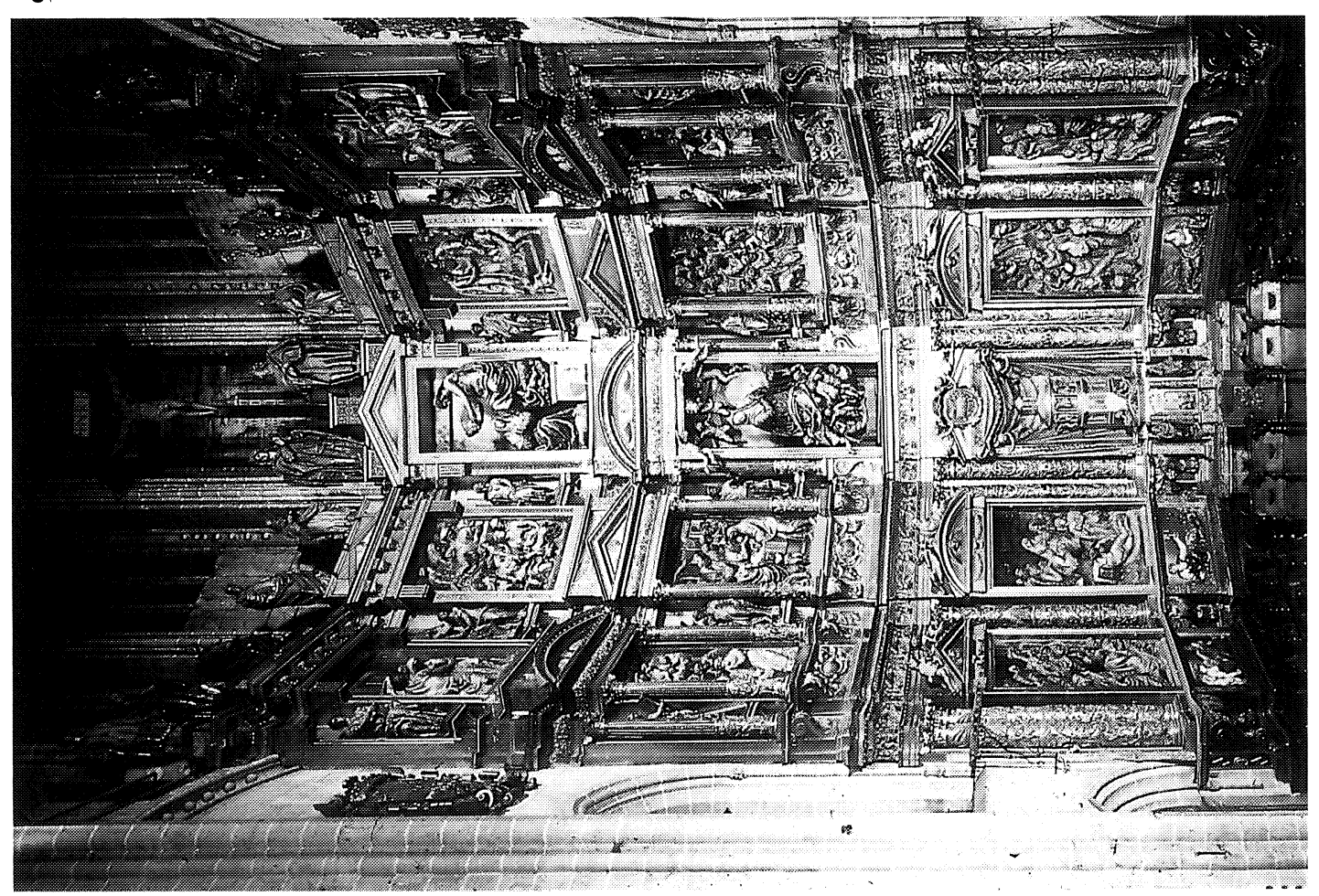


siásticas pudieran visualizar el efecto que tendrían las otras historias del retablo: «ante todas cosas haré la ystoria dela asunción de nra señora conforme a la alteza del encaje a donde se a de asentar para que bista esta ystoria [...] y me obligo a fazer todas las otras fyguras que fueren en la dicha obra conforme a esta dicha ystoria que se entiende en bondad y bien hecha» ${ }^{16}$.

La seguridad en su enfoque escultórico es evidente cuando Becerra decide que si el cabildo no aprueba el trabajo hecho, él no se encargará del retablo catedralicio y se le pagaría sólo por este trabajo. Becerra probablemente tomó esta iniciativa debido a sus circunstancias personales y no solamante como Martín González indicó, para demostrar su «honradez profesional» ${ }^{17}$. Esta excepción, de parte del artista, ciertamente pone a luz el desconocimiento visual acerca de las habilidades escultóricas del artista en España. Los eclesiásticos astorganos, con toda seguridad, habrán conocido las obras de los otros cinco escultores, pero no las de Becerra; lo cual no sería sorprendente, ya que éste último, al regresar de Roma, no había pasado suficiente tiempo en Valladolid como para demostrar las destrezas requeridas para enfrentar una obra escultórica y arquitectónica de tal magnitud.

Un denominador común de los proyectos para el concurso del retablo mayor es que no se concentran en el dorado, estofado y pintura de la obra. El contrato para llevar a cabo este trabajo se estipula el 5 de diciembre de 1569, con Gaspar de Hoyos y Gaspar de Palencia ${ }^{18}$.

El obispo y el cabildo de la catedral de Astorga decidieron adjudicar a Becerra la responsabilidad de la ejecución del retablo mayor ${ }^{19}$. Becerra firmó el contrato ante el notario Iñigo de Miranda, el 8 de agosto de 1558 y su propuesta fue añadida al mismo documento, pero su traza, que él declaró haber firmado y entregado al notario, no se encontró hasta hoy día.

La paternidad de la obra catedralicia a Becerra, queda corroborada con «las cartas de pago» que al artista recibió para la ejecución del retablo mayor de la catedral, que descubrí en el Archivo Diocesano de Astorga. Estos documentos son de gran importancia porque también nos permiten establecer los extremos cronológicos de esta obra monumental. Becerra no fue fiel a su promesa de acabar el retablo en 1560 , pero tampoco la obra quedó terminada en 1562, como tradicionalmente se cree, basado en el hecho documentado del comienzo de la carrera de Becerra en la corte de Felipe II en Madrid ${ }^{20}$.

La mayoría de las condiciones de pago requeridas por Becerra el 8 de agosto de 1558 no se cumplieron. El artista había demandado que los 3.000 ducados se le distribuyera de la siguiente manera: 200 ducados para empezar a trabajar en septiembre de 1558, o sea un mes después de firmar el contrato; 500 ducados para cuando tomase residencia fija en Astorga en noviembre de 1558; 700 ducados, al cumplirse ocho meses de haberse mudado de Valladolid en julio de 1559; otros 700 ducados ocho meses más tarde, en marzo de 1560; y 900 ducados en agosto o en septiembre de 1560, para cuando el retablo mayor quedase terminado ${ }^{21}$. En cambio, él recibió 2.932 ducados y 100 reales, desde septiembre de 1558 a octubre de 1563.

El primer pago conferido a Becerra por el cabildo de la Catedral de Astorga fue el 23 de septiembre de 1558. La suma recibida fue de 200 ducados, para dar inicio al retablo mayor del templo astorgano: «Sepan quantos esta carta de pago bieren como yo, gaspar bezerra, pintor y escultor, vezino de la villa de valladolid, estante al presente en esta çiudad de astorga, que otorgo y conozco por esta presente carta, que rreçibí [...] en nombre de la fábrica de la dicha yglesia, $[\ldots]$ dos myll e duzientos rreales en rreales [...] para en quenta e pago de los maravedís que me

16 Ibidem, pp. 175-176.

${ }_{17}$ Martín González, op. cit., p. 341.

${ }^{18}$ Rodríguez López, op. cit., pp. 53-54, 181-195 y Rodríguez Díez, op. cit., pp. 541, 811-820.

19 Rodríguez López, p. 178.

${ }^{20}$ Llaguno y Amírola, E.: Noticias de los arquitectos y arquitectura de España desde su restauración, ilustradas y acrecentadas con notas, adiciones y documentos por Don J. A. Céan Bermúdez, vol. 1, Madrid, 1829, pp. 259-261.

${ }^{21}$ Rodríguez López, op. cit., p. 176. 
an de dar y pagar por rrazón del dicho rretablo que ansi tengo de hazer para la dicha yglesia» ${ }^{22}$. Este documento, donde consta que Becerra todavía residía en Valladolid, constituye la prueba de que el artista efectivamente dio comienzo a la obra después de septiembre de 1558, al mes de haber firmado el contrato, como él se había comprometido. Con excepción del segundo pago demandado por el artista con plazo de enero de 1559, todos los pagos posteriores recibidos en los meses y años exigidos por el artista, se conservan. El 31 de julio de 1559, supuestamente seis meses después de que Becerra sentara residencia en Astorga, éste acusó recibo de 200 duca$\operatorname{dos}^{23}$. En este documento, efectivamente consta, que Becerra ya residía en Astorga: «gaspar bezerra, estante y rresidente al presente en la çiudad de astorga». A partir de ese momento a Becerra también se lo califica de «maestro del rretablo, que de presente se faze para la santa yglesia catedral de nuestra señora santa maría de esta dicha çiudad de astorga» y se especifica que el dinero recibido es por razón de esta obra escultórica.

Becerra recibió otros 100 ducados el 23 de noviembre del $1559^{24}$ y el 12 de marzo del año siguiente, aceptó 300 ducados ${ }^{25}$.

En lugar de acusar recibo por última vez, en septiembre de 1560, cuando se pensaba que el retablo estaría concluido, Becerra recibió 100 ducados más en tres ocasiones: el 10 de julio, el 14 de agosto y el 16 de septiembre de ese año ${ }^{26}$. En 1561, recibió 734 ducados, pagados en siete plazos: 160 ducados el 14 de mayo, 100 ducados el 27 de junio, 18 de julio y el 13 de agosto, 74 ducados el 26 de septiembre y 100 ducados el 31 de octubre y el 19 de noviembre ${ }^{27}$. En el 1562, Becerra pidió prestado dinero a la Catedral de Astorga, como demuestran los cinco documentos de obligación en donde el artista devuelve el dinero a dicha institución: 100 ducados el 12 de marzo y el 10 de abril; 150 ducados el 15 de junio; 50 ducados el 7 de agosto y 44 ducados el 21 del mismo mes ${ }^{28}$. El 14 de enero de 1563, Becerra prometió liquidar toda la deuda contraída en el año anterior, que según sus testigos sumaba a 504 ducados y 100 reales $^{29}$. Los testigos, que

22 «Carta de pago q[ue] dio gaspar bezerra de dos myll e duzientos r[eal]es», 23 de septiembre de 1558, 1 fol. Leg.: Íñigo de Miranda-1558 (sin catalogar), A.D.A., fol 1v. 2.200 reales equivale a 200 ducados.

${ }^{23}$ «Carta de pago $\mathrm{p}$ [ar]a p[edr]o fernández administrador de dos myll quinientos rreales p[ar]a en quenta del rretablo», 31 de julio de 1559, 1 fol. Leg.: Íñigo de Miranda- 1560 y otros n. ${ }^{\circ} 1$, A.D.A., fol. 1v.

24 «Carta de pago q[ue] dio gaspar bezerra de myll çien rreales p[ar]a en q[uen]ta del rretablo q[ue] faze enesta yglesia», 23 de noviembre de 1559, 1 fol. Leg.: Íñigo de Miranda-1560 y otros n. ${ }^{\circ}$ 1, A.D.A., fol. 1v.

25 «Carta de pago q[ue] dio bezerra maestro del rretablo de tres mjl e çiento e çinquenta rreales», 12 de marzo de 1560 , 1 fol. Leg.: Íñigo de Miranda-1560-2. ${ }^{\circ}$ A.D.A.

26 «Ca[rta] de pago de çien du[cad]os e[n] q[uen]ta a gaspar bezerra maestro del rretablo», 10 de julio de 1560,1 fol. Leg.: Íñigo de Miranda-1560 y otros n. ${ }^{\circ}$ 1, A.D.A; «Ca[rta] de pago q[ue] dio gaspar bezerra maestro del rretablo de myll çien rreales», 14 de agosto de 1560, 1 fol. Leg.: Íñigo de Miranda-1560-2. ${ }^{\circ}$ A.D.A.; y «Carta de pago de myll e çien rreales q[ue] dio gaspar bezerra q[ue] rreçibió p[ar]a e[n] q[uen]ta del rretablo q[ue] faze», 16 de septiembre de 1560, 1 fol. Leg.: Íñigo de Miranda-1560-2. ${ }^{\circ}$ A.D.A.

${ }^{27}$ En Leg.: Íñigo de Miranda-1561-1. ${ }^{\circ}$ A.D.A.: «Carta de pago q[ue] dio gaspar bezerra de clx du[cad]os p[ar]a en q[uen]ta del rretablo de la obra», 14 de mayo de 1561, 1 fol.; «Carta de pago que dio gaspar bezerra de çien du[cad]os q[ue] rre[cibió] de p[edr]o fernández can[ónig]o p[ar]a e[n] q[uen]ta del rretablo», 27 de junio de 1561, 1 fol.; «Carta de pago de çien du[cad]os en rreales a gaspar bezerra maestro del rretablo», 18 de julio de 1561, 1 fol.; «Carta de pago q[ue] dio gaspar bezerra de çien du[cad]os del retablo...», 13 de agosto de 1561, 1 fol.; «Carta de pago que dio gaspar bezerra de ochoçientos e diez y ocho rreales..., 26 de septiembre de 1561, 1 fol.; «Carta de pago q[ue] dio gaspar bezerra de çien du[cad]os en rr[eal]es», 31 de octubre de 1561, 1 fol.; y «Carta de p[ag]o q[ue] dio gaspar bezerra pintor de çien $\mathrm{d}[\mathrm{ucad}] \mathrm{os}$ p[ar]a en q[uen]ta del rretablo», 19 de noviembre de 1561,1 fol.

${ }^{28}$ En Leg.: Íñigo de Miranda-1562-2. ${ }^{\circ}$, A.D.A.: «Obligación q[ue] hizo gaspar bezerra e su muger al lic[encia]do açeuedo de c du[cad]os», 12 de marzo de 1562, 2 fols.; «Oblig[aci]ón que hizo gaspar bezerra maestro del rretablo al lic[encia]do aceuedo de c du[cad]os q[ue] le prestó», 10 de abril de 1562, 2 fols.; «Oblig[aci]ón que hizo gaspar bezerra e su muger al s[eñor] lic[encia]do azebedo de cl du[cad]os en rreales», 15 de junio de 1562, 2 fols.; «Obligación que hizo gaspar bezerra a su muger de 1 ducados», 7 de agosto de 1562, 2 fols; y «Oblig[aci]ón de la fábrica desta y[glesia] s[an]ta de bezerra», 21 de agosto de 1562,2 fols.

${ }^{29}$ «Oblig[aci]ó[n] de la fábrica de la y[gle]sia cathedral de los dineros que se dieron a bezerra pintor», 14 de enero de 1563, 2 fols. Leg.: Íñigo de Miranda-1563, A.D.A. 
fueron los pintores Pedro de Bilbao y Pedro de Bilches y los plateros Sebastián de Encalada y Francisco de Soto, dan una cuenta detallada de los préstamos de Becerra: 100 ducados el 5 de marzo y el 2 de abril; 150 ducados el 15 de junio; 50 ducados el 7 de agosto; 44 el 21 de agosto y otros 70 ducados, prestados a Paula Velázquez, mujer de Becerra. Nueve meses más tarde, en el mismo documento, el notario Iñigo de Miranda, declaró la cancelación de la deuda de Becerra, de parte de Juan de Acevedo, administrador de la Catedral. Toda la deuda de Becerra, fue anulada y considerada como pago que el artista había recibido de parte de la Catedral por razón del retablo. De hecho, en la misma fecha del 13 de octubre de 1563, Becerra, con otro documento, notificó que había recibido la suma de 504 ducados y 100 reales por el retablo catedralicio $^{30}$.

La última carta de pago a Becerra, identificada en el Archivo Diocesano de Astorga, es el recibo de 150 ducados con fecha del 29 de octubre de 1563. En este documento se declara que Becerra sigue a cargo de la obra catedralicia: «yo, gaspar bezerra, pintor, maestro del rretablo de la santa yglesia de astorga, otorgo e conozco por esta presente carta, que rresçibí [...] myll e seyçientos e çinquenta rreales [...] los quales son para en quenta e pago del rretablo que hago para la dicha yglesia cathedral de astorga» ${ }^{31}$.

Becerra continuaba involucrado con su obra escultórica y arquitectónica hasta casi finales del 1563, al mismo tiempo que trabajaba en Madrid en el palacio de El Pardo, desde septiembre de 1562. En la cédula real de su nombramiento oficial, el 23 de agosto de 1563, se le exigía a Becerra la residencia en la corte, al mismo tiempo, que en otra cédula expedida en la misma fecha, se le concedía al artista la autorización de ausentarse de la corte y de sus trabajos de El Pardo, por un total de 40 días, a partir del 1 de septiembre de $1563^{32}$. La razón de su ausencia no se especifica, pero lo obvio sería pensar que Becerra fue a Astorga a terminar el retablo mayor de la Catedral y a inspeccionar el trabajo de su taller. De hecho, como se ha visto, en el penúltimo recibo astorgano de pago, de octubre de 1563, al artista se lo menciona como «estante» en Astorga, indicando que él ya no residía en esta ciudad, mientra que en enero del mismo año a él se lo citaba todavía como residente en Astorga: «gaspar bezerra, pintor, y paula belázquez, su muger, vezinos de la dicha çiudad de astorga».

El retablo mayor de la catedral astorgana (Fig. 9), siguió fielmente el proyecto de Becerra, con pocos cambios substanciales, referentes en su mayoría, a la reducción del número de esculturas exentas planeadas, como ya lo había advertido Martín González.

Los documentos de pago que hemos estudiado constituyen la primera evidencia documental de Becerra como escultor. Apesar de que en la mayoría de los recibos de pago, se le define a Becerra solo como pintor, su estatus de escultor se reconoce, como se ha visto, en el contrato estipulado para el retablo catedralicio en agosto de 1558 y un mes más tarde, el 23 de septiembre, cuando el artista recibió el primer pago antes de dar comienzo a la obra. Es interesante notar que a Becerra también se le define como «entallador», según aparece en el encabezamiento del documento de poder del 15 de mayo de 1562 de la mujer de Becerra, Paula Velázquez, a su marido que se encontraba en Valladolid, para que cobrara 50 ducados de su parte ${ }^{33}$. Consta además, en el recibo de pago del 12 de marzo de 1560, que al artista se le pagó por la maqueta del reta-

\footnotetext{
30 «Carta de pago que dio gaspar bezerra pintor al señor licenciado juan de acevedo de quinientos e quatro ducados e cien rreales más par en quenta del rretablo que haze e nesta yglesia», 13 de octubre de 1563, 1 fol. Leg.: Íñigo de Miranda-1563, A.D.A., fol. 589v.

${ }^{31}$ Las cursivas son mías. «Carta de pago q[ue] dio gaspar bezerra pintor al s[eñor] li[cencia]do azebedo de mcl rreales pa[ra] en q[uen]ta del rretablo», 29 de octubre de 1563, 1 fol. Leg.: Íñigo de Miranda-1563, A.D.A., fol. 616v.

${ }^{32}$ Llaguno y Amírola, op. cit., p. 261.

33 «Poder q[ue] dio su muger de bezerra entallador ve[zin]o desta çiudad», 15 de mayo de 1562, 2 fols. Leg.: Íñigo de Miranda-1562-2. ${ }^{\circ}$ A.D.A.
} 
blo mayor y por la traza: «bieren como yo, gaspar bezerra, [...] rreçibí [...] tres myll e çiento e çinquenta rreales [...] los quales me distes y pagastes [...] e más [...] çiento e çinquenta rreales que me dio, por la muestra e traza que fize del dicho rretablo» ${ }^{34}$.

Otros contratos y/o pagos de retablos y tabernáculos que Becerra recibió en la diócesis astorgana, también reconocen la posición del artista como escultor y entallador ${ }^{35}$. Estos documentos y otros referentes a la actividad artística de Becerra en la diócesis de Astorga, son reveladores porque constituyen la evidencia de las múltiples habilidades de Becerra como pintor, dorador, estofador de retablos y custodias, y creador de altares escultóricos y de tabernáculos ${ }^{36}$.

Las cartas de poder que presentó Becerra en 1562, a la administración de la catedral de Astorga, son también de suma importancia porque citan los nombres de algunos de los artistas que pertenecían a su taller: «miguel de rribas e paulo de montoya»; «baltasar del torneo»; «bernal de gabadi»; «pedro de bilbao e andrés garcía, pintores vecinos de esta çiudad»; «lope flórez»; «pedro de bilches, pintor, sebastián de encalada, francisco soto, plateros, e pedro de biluao, vezinos de la çiudad de astorga».

La adjudicación de la ejecución de este retablo monumental a Becerra, de parte del obispo y del capítulo de la catedral de Astorga, despierta algunas interrogantes: ¿por qué no eligieron a Picardo o a Alvarez que estaban afirmados en la práctica de retablos escultóricos y enraizados en la tradición «moderna» de Juni y Berruguete? o ¿por qué escogieron a Becerra que había llegado recientemente de Roma, donde había trabajado principalmente como pintor de frescos desde 1545 a $1556 ?$

No cabe duda que si las autoridades eclesiásticas hubieran elegido el proyecto de Picardo y Andrés, la tradición de Juni habría continuado. La adjudicación de esta obra monumental a Becerra fue, en cambio, decisiva para la evolución del retablo en el último tercio en España, aspecto que fue siempre claramente reconocido por los historiadores de arte españoles.

La elección de Becerra no fue un riesgo. Al contrario, ésta revela el conocimiento del obispo de Astorga, Don Diego Sarmiento de Sotomayor, de las últimas tendencias artísticas romanas y la habilidad del baezano en traducirlas a la tradición española del retablo policromado. La tendencia de Becerra a una mayor racionalización y claridad de la estructura arquitectónica y la compenetración e interdependencia de ésta con sus esculturas y relieves, ciertamente no se explican sin la formación que éste adquirió en el círculo del pintor y escultor Daniele da Volterra (1547-1550). Tampoco sin el estudio o participación directa de Becerra en las decoraciones de estuco del Palazzo Spada (1550-1555), dirigidas por su colega Giulio Mazzoni. La evidencia concreta de la total asimilación de parte de Becerra de la idea renacentista italiana de la práctica de la pintura, escultura y arquitectura, antes de regresar a España, es la decoración recientemente documentada, que este artista llevó a cabo en la capilla de Nuestra Señora de la Asunción de la iglesia de Santiago de los Españoles (c. 1552-1556), completada por Mazzoni ${ }^{37}$.

La clave de la adjudicación del concurso del retablo mayor de la catedral de Astorga a Gaspar Becerra reside no solamente en la formación italiana del artista, pero también en las conec-

${ }^{34}$ Las cursivas son mías. 12 de marzo de 1560, 1 fol. Leg.: Íñigo de Miranda-1560 y otros n. ${ }^{\circ}$ 1, A.D.A., fol. 1v.

${ }^{35}$ González García, M. A.: «Los retablos manieristas de Casaio y Casoio en Valdeorras (Orense)», Porta da Aira, vol. I, 1988, pp. 36-37. «Tasaçiones de la custodia de soto de la bega de talla y pintura», 23 de mayo de 1564, Leg.: Antonio Rodríguez -1564 (sin catalogar), 2 fols, A.D.A.

${ }^{36}$ Voces Jolías, J. M.: Arte religioso de El Bierzo, Ponferrada, 1987, pp. 456-462. En el documento de «tasaçión dela custodia de san martín de torres», 14 de abril de 1562, 2 fols. Leg.: Íñigo de Miranda 1562-2, A.D.A., se declara que Becerra ejecutó el dorado, la pintura y el estofado, además de «la talla de la d[ic]ha custodia con sus bultos y con todas sus colunas q[ue] son quarenta y dos» (fol. 263r).

37 Carmen Fracchia, Gaspar Becerra y el retablo mayor de la Catedral de Astorga, Tesis Doctoral, agosto, 1996. 
ciones que el obispo de Astorga tenía con la corte papal y con la iglesia de Santiago de los Españoles en Roma, que pudieron haberle recomendado personalmente las habilidades escultóricas del andaluz ${ }^{38}$. Estos son los factores que contribuyeron, sin lugar a dudas, a aclamar la victoria de Becerra en el concurso escultórico del retablo mayor de la Catedral de Astorga a mediados del siglo XVI.

CARMEN FRACCHIA

Universidad de Londres

\section{RELACIONES ENTRE EL PINTOR ALONSO SÁNCHEZ COELLO Y LA FAMILIA FARNESIO}

Aunque el pintor valenciano Alonso Sánchez Coello cultivó otros géneros pictóricos como el religioso, su fama proviene de su faceta como retractista de la casa real. Tras una primera formación en la corte portuguesa y en Flandes junto a su maestro Antonio Moro, le encontramos, desde 1555, al servicio de Felipe II para quien realizó múltiples encargos hasta su muerte, el 8 de agosto de 1588. Pacheco nos relató los numerosos favores con que le obsequiaba Felipe II, quien, de creer al tratadista, visitaría asiduamente su taller como otrora hiciera Alejandro con Apeles, pero también su arte sería admirado a nivel internacional por personajes de la talla de «los papas Gregorio XIII y Sixto V, los grandes duques de Florencia y de Saboya y el cardenal Alejandro Farnesio, hermano del Duque de Parma» ${ }^{1}$. Hasta que R. M. Mulcahy no dio a conocerr siete cartas de la correspondencia entre el pintor y el cardenal Farnesio ${ }^{2}$ y C. Robertson las gestiones de este último para conseguir una vacante para el hijo del pintor ${ }^{3}$, no se pudieron demostrar documentalmente estas relaciones artísticas materializadas en varios retratos.

Todos los indicios apuntan a que el primer miembro de la familia Farnesio con el que Sánchez Coello mantiene contactos es con el joven Príncipe de Parma y Piacenza, Alejandro, a quien retrata en $1561^{4}$ cuando se encontraba en la corte de su tío Felipe II. El fin de esta obra sería el de integrarse en una galería de retratos o quizá ser enviada a los Duques de Parma, los progenitores del Príncipe, para informarles del óptimo desarrollo de éste ${ }^{5}$ y atenuar las sospechas farnesianas que vieron los designios ${ }^{6}$ de Felipe II casi como un «secuestro». Margarita de

38 Ver nota anterior.

1 Pacheco, F., Arte de la Pintura, ed. a cargo de J. Sánchez Cantón, Madrid, 1956, pp. 146 y 147.

2 Mulcahy, R. M., «Alonso Sánchez Coello and Cardinal Alessandro Farnesse», Burlington Magazine, mayo 1992, pp. 305-308.

${ }^{3}$ Robertson, C., «Il Gran cardinale», Alessandro Farnese, Patron of Arts, New Haven, 1992.

${ }^{4}$ Este retrato pertenece a la Algur H. Meadows Collection. Meadows Museum, Southern Methodist University, Dallas, Texas. Cat. Alonso Sánchez Coello y el retrato en la corte de Felipe II, Madrid, 1990, p. 147, n. ${ }^{\circ} 30$. Se conserva una copia de medio cuerpo en la Galleria Nazionale de Parma. M Kusche en su estudio «Sofonisba e il ritratto di rappresentanza ufficiale nella corte spagnola», en el catálogo Sofonisba Anguissola e le sue sorelle, Cremona, 1994, p. 133, se lo atribuye a Antonio Moro, pero se debe tener en cuenta que Moro abandona la corte española en 1560.

5 Este fue el destino del retrato del Príncipe realizado por Antonio Moro en 1557. Sobre este tema, véase Meijer, B., Parma e Bruxelles. Committenza e collezionismo farnesiani alle due corti. Parma, 1988, pp. 120-125.

${ }^{6}$ Una de las cláusulas del tratado secreto de Gand, firmado entre Felipe II y los Farnesio en 1556, era la de enviar a la corte de Felipe II al joven heredero de Ottavio Farnesio para que fuese allí educado. De esta manera, Felipe II se aseguraría la fidelidad de los Farnesio y pondría fin a las veleidades de esta familia con Francia. Para profundizar en este tema, resulta fundamental la obra de Drei, G., I Farnese. Grandezza e decadenza di una dinastia italiana, Roma, 1954, caps. VIII y IX. 